\title{
Frequency of Latent TB Infection in Patients with Spondyloarthritis in a Tertiary Care Hospital in Bangladesh
}

\author{
Abu Tahir Muhammad Tanveer Hasan ${ }^{1, ~ *, ~ M u h a m m a d ~ A b d u l ~ A l i m ² ~}$ \\ ${ }^{1}$ Department of Rheumatology, Enam Medical College \& Hospital, Dhaka, Bangladesh \\ ${ }^{2}$ Centre for Rheumatic Care \& Research, Green Life Hospital, Dhaka, Bangladesh
}

Email address:

rousseau150.dmc@gmail.com (A. T. M. T. Hasan), abdul265alim@gmail.com (M. A. Alim)

${ }^{*}$ Corresponding author

\section{To cite this article:}

Abu Tahir Muhammad Tanveer Hasan, Muhammad Abdul Alim. Frequency of Latent TB Infection in Patients with Spondyloarthritis in a Tertiary Care Hospital in Bangladesh. American Journal of Biomedical and Life Sciences. Vol. 8, No. 6, 2020, pp. 202-205. doi: $10.11648 /$ j.ajbls.20200806.12

Received: October 17, 2020; Accepted: November 2, 2020; Published: November 9, 2020

\begin{abstract}
Background \& Objective: Screening for latent TB infection is recommended prior to the initiation of the newer and more effective treatment modalities of spondyloathritis such as biologic agents and tofacitinib. The prevalence of latent TB infection in the adult population of Bangladesh is not yet known. The figure is $40 \%$ in the general population in India that is demographically similar to the Bangladeshi population. The objective of this study was to assess the frequency of latent TB infection in patients with spondyloarhtritis visiting a tertiary hospital. Materials \& Methods: This study was conducted in the Department of Rheumatology of Enam Medical College \& Hospital, Savar, Dhaka, Bangladesh from October 2018 to December 2019. Each of the 75 participants underwent Mantoux test as a screening procedure for the detection of latent TB infection. Results: Mantoux test was positive ( $\geq 10 \mathrm{~mm}$ ) in $10.3 \%$ of the participants. A reading between 5 and $9 \mathrm{~mm}$ was found in $33.7 \%$ of the participants and the rest of the participants (56\%) had induration diameters $<5 \mathrm{~mm}$ ). $44 \%$ of the participants had readings $\geq 5 \mathrm{~mm}$. Conclusions: A lower than expected (around 40\%) frequency of latent TB infection was found among the participants. But using a cut-off value of $5 \mathrm{~mm}$ yields a frequency of $44 \% \%$ that is close to our expectation. So a lower cut-off value for the interpretation of Mantoux test in patients with spondyloarthritis may be appropriate. A larger-scale study is required to confirm this observation.
\end{abstract}

Keywords: Spondyloarthritis, Latent TB Infection, Mantoux Test

\section{Introduction}

The spondyloarthritis $(\mathrm{SpA})$ family comprises ankylosing spondylitis (AS), nonradiographic axial SpA (nr-axSpA), peripheral SpA, psoriatic arthritis, SpA associated with Crohn's disease and ulcerative colitis, reactive arthritis and juvenile-onset $\mathrm{SpA}$ [1]. The point prevalence of spondyloarthritis in Bangladesh is $1.2 \%$ [2]. The major clinical features which differentiate spondyloarthritis (SpA) from other forms of arthritis are the distribution and type of musculoskeletal manifestations and certain extraarticular features. Patients with axial $\mathrm{SpA}$ characteristically have chronic low back pain. Patients with either axial or peripheral SpA can exhibit peripheral musculoskeletal features, which include dactylitis (sausage digits), enthesitis (heel pain and/or swelling), and peripheral arthritis [1]. The reasons for the classification of $\mathrm{SpA}$ into categories are both historical and practical, but each category does not necessarily represent a discrete entity - the clinical, laboratory, and imaging findings can overlap. The diagnosis and management approaches for patients suspected of having any type of $\mathrm{SpA}$ are also similar in general $[3,4]$.

Biologic DMARDs and tofacitinib are amongst the latest additions to the treatment of spondyloarthritis that is refractory to NSAIDs and conventional DMARDs $[5,6]$. However, there is an increased risk of mycobacterial infections in patients on biologics [7]. A study showed tuberculosis to be the most common opportunistic infection in patients treated with tofacitinib [8]. Hence, it is recommended to screen for latent TB infection (LTBI) in patients prior to initiation of biologics \& tofacitinib $[9,10]$. 
Tuberculin skin (Mantoux) test (TST) for the detection of TB infection is among the oldest tests in medicine, developed by Charles Mantoux between 1907-12 [11]. Despite problems and controversies, TST has been widely used around the world to estimate the prevalence of LTBI in the population $[12,13]$. In Bangladesh, there is as yet no data on the national prevalence of LTBI in the adult population. A study conducted on Bangladeshi children aged 3-12 years found that the prevalence of LTBI among children who had household TB contact was $41.5 \%$, and $9.2 \%$ among children who did not have household TB contact [14]. The aim of this study was to find out the frequency of LTBI in adult patients with spondyloarthritis in a tertiary hospital.

\section{Materials and Methods}

This study was conducted in the Department of Rheumatology of Enam Medical College \& Hospital, Savar, Dhaka, Bangladesh from October 2018 to December 2019. 75 patients with spondyloarthritis were recruited and they underwent Mantoux test with tuberculin PPD IP (10 TU/0.1 $\mathrm{mL}$ ) that was injected intradermally into the ventral aspect of the forearm and the patient was asked to return between 48 and 72 hours. The diameter of the induration (if any) was measured and recorded. The test was considered to be positive if the diameter of the induration was $\geq 10 \mathrm{~mm}$. In our study, we could not perform Interferon gamma release assay (IGRA) to detect LTBI due to budget constraint.

\section{Results}

Ages of the respondents varied from 18 to 65.75 years. The mean age of was 40.74 years. $26 \%$ of them was males and $74 \%$ of them was females. The female preponderance of the respondents may be explained by the fact that they were picked up mainly during the morning OPD hours when most of the males have to stay in the workplace. Mantoux test was positive $(\geq 10 \mathrm{~mm}$ ) in $10.7 \%$ of the participants. A reading between 5 and $9 \mathrm{~mm}$ was found in $33.3 \%$ of the participants and the rest of the participants (56\%) had induration diameters $<5 \mathrm{~mm}$ (figure 1).

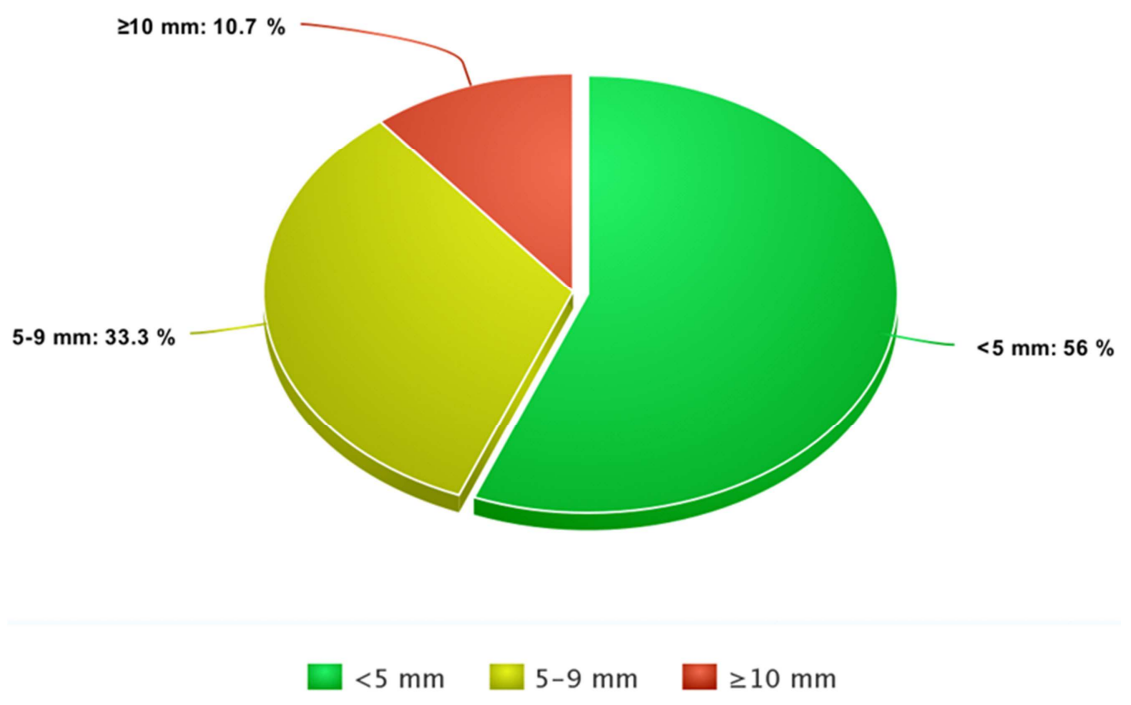

Figure 1. Distribution of Respondents According to MT Test Response.

So $44 \%$ of the participants had readings $\geq 5 \mathrm{~mm}$ (figure 2 ).

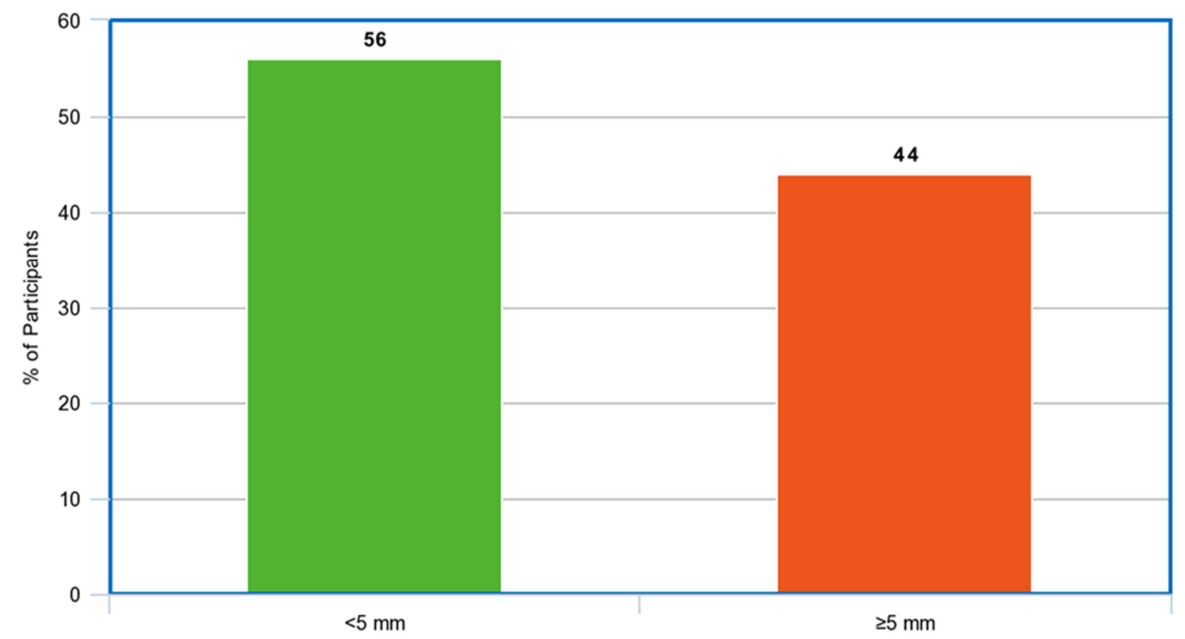

Figure 2. Distribution of Respondent as per MT Test Response (Cut-Off: $5 \mathrm{~mm}$ ). 


\section{Discussion}

The frequency of positive Mantoux test response in our study $(10.8 \%)$ was much lower than that found in a study (54\%) conducted among health care workers in chest disease hospitals of Bangladesh [15]. This difference can readily be explained by the greatly increased risk of contact of those health care workers with TB patients. But interestingly, the finding in our study is also much lower than the prevalence of latent TB infection in the general Indian population, which is $40 \%$ [16].

According to WHO, the incidence of tuberculosis in Bangladesh was 221 per 100000 population and that in India was 199 per 100000 population in 2018 [17, 18]. Considering the geographical proximity of Bangladesh and India, similar demography and similar incidence of tuberculosis, it may be assumed that the prevalence of LTBI in Bangladesh would be similar to that of India, i.e. around $40 \%$. But in our study the frequency of LTBI is much lower, if $10 \mathrm{~mm}$ is used as the cut-off value for a positive result. Interestingly, if we use a cut-off value of $5 \mathrm{~mm}$, the frequency of LTBI in the study sample becomes $44.6 \%$ which is close to the prevalence of LTBI in the general Indian population. So a Mantoux test cut-off value of $5 \mathrm{~mm}$ may be more appropriate for patients with spondyloarthritis possibly because of attenuated immune response. This attenuation may be due to the inherent immunosuppressive effect of the underlying autoimmune inflammatory rheumatic disease (AIIRD) itself as well as due to the effect of the immunomodulatory therapies used in treatment of AIIRD [19]. Some but not all of the patients in our study were on immunosuppressive therapy. Before proposing such a modified cut-off value, we would like to recommend conduction of a large-scale study assessing and comparing frequencies of LTBI among spondyloarthritis patients with and without immunosuppressive therapy using the conventional cut-off value of $10 \mathrm{~mm}$ and the proposed cut-off value of $5 \mathrm{~mm}$.

\section{Conclusion}

The frequency estimate of latent TB infection in our study population depends on the cut-off value of Mantoux test. A cut-off value of $5 \mathrm{~mm}$ yields a frequency of $44 \%$ (which is similar to that in the general Indian population), whereas a cutoff value of $10 \mathrm{~mm}$ offers a frequency of $10.7 \%$ only. Hence the cut-off value for Mantoux test positivity in patients with spondyloarthritis may need to be. A larger-scale and welldesigned study is required to address the issue systematically.

\section{References}

[1] Yu DT, van Tubergen A. Overview of the clinical manifestations and classification of spondyloarthritis. UpToDate. Sieper J, Romain PL, ed. UpToDate. Maltham, MA: UpToDate Inc. Available from: (Updated 7 September 2018, cited 17 December 2019).
[2] Ahmed S, Haq SA, Al-Qadir AZ, Rahman MM, Paul S. Survey on prevalence of rheumatic disorders in Bangladeshi adults. Ann Rheum Dis. 2017; 76 (2): 1044-1045.

[3] Zeidler H, Amor B. The Assessment of Spondyloarthritis International Society (ASAS) classification criteria for peripheral spondyloarthritis and for spondyloarthritis in general: the spondyloarthritis concept in progress. Ann Rheum Dis 2011; 70 (1): 25-31.

[4] Zeidler H, Calin A, Amor B. A historical perspective of the spondyloarthritis. Curr Opin Rheumatol 2011; 23 (4): 327-333.

[5] van der Heijde D, Ramiro S, Landewé R, Baraliakos X, Van den Bosch F, Sepriano A, Regel A, Ciurea A, Dagfinrud H, Dougados M, van Gaalen F. 2016 update of the ASAS-EULAR management recommendations for axial spondyloarthritis. Annals of the rheumatic diseases. 2017 Jun 1; 76 (6): 978-91.

[6] Gossec L, Smolen JS, Ramiro S, De Wit M, Cutolo M, Dougados M, Emery P, Landewé R, Oliver S, Aletaha D, Betteridge N. European League Against Rheumatism (EULAR) recommendations for the management of psoriatic arthritis with pharmacological therapies: 2015 update. Annals of the rheumatic diseases. 2016 Mar 1; 75 (3): 499-510.

[7] Kourbeti IS, Ziakas PD, Mylonakis E. Biologic therapies in rheumatoid arthritis and the risk of opportunistic infections: a meta-analysis. Clinical Infectious Diseases. 2014 Mar 18; 58 (12): $1649-57$.

[8] Winthrop KL, Park SH, Gul A, Cardiel MH, Gomez-Reino JJ, Tanaka Y, Kwok K, Lukic T, Mortensen E, de Leon DP, Riese R. Tuberculosis and other opportunistic infections in tofacitinib-treated patients with rheumatoid arthritis. Annals of the rheumatic diseases. 2016 Jun 1; 75 (6): 1133-8.

[9] Holroyd CR, Seth R, Bukhari M, Malaviya A, Holmes C, Curtis E, Chan C, Yusuf MA, Litwic A, Smolen S, Topliffe J. The British Society for Rheumatology biologic DMARD safety guidelines in inflammatory arthritis. Rheumatology. 2018 Aug 21; 58 (2): e3-42.

[10] Singh JA, Saag KG, Bridges Jr SL, Akl EA, Bannuru RR, Sullivan MC, Vaysbrot E, McNaughton C, Osani M, Shmerling RH, Curtis JR. 2015 American College of Rheumatology guideline for the treatment of rheumatoid arthritis. Arthritis \& rheumatology. 2016 Jan; 68 (1): 1-26.

[11] Anand NM, Vishal KA, Kalyani A, Sadhana SB. Tuberculin Skin Test for the Screening of Latent Tuberculosis Infection Before Starting Treatment with Tumour Necrosis Factor- $\alpha$ Inhibitors In Systemic Immunoinflammatory Rheumatic Diseases in India-A High Burden Tuberculosis Region of the World. J Rheumatol Arthritic Dis. 2018; 3 (2): 1-6.

[12] Daniello J, Zöllner I. Experiences with the intracutaneous Mendel-Mantoux tuberculin test in routine screening in a public health office. Gesundheitswesen (Bundesverband der Arzte des Offentlichen Gesundheitsdienstes (Germany)). 1997; 59 (8-9): 519-22.

[13] Dye C, Scheele S, Pathania V, Raviglione MC. Global burden of tuberculosis: estimated incidence, prevalence, and mortality by country. Jama. 1999 Aug 18; 282 (7): 677-86.

[14] Islam, S., Chowdhury, S., Karim, M., Samad, R., Barua, P., \& Chowdhury, Z. (2017). Prevalence of Latent Tuberculosis Among Children Living in Households with Smear Positive Pulmonary Tuberculosis Patients. Bangladesh Medical Research Council Bulletin, 42 (2), 67-71 
[15] City B. Latent tuberculosis infection among healthcare workers in chest disease hospitals. Bangladesh. Health and Science Bulletin. 2014 Mar; 12 (1).

[16] Kanabus A. TB statistics India. UK: Global Health Education (GHE); (updated October 2019, cited 29 December 2019). Available from: https://tbfacts.org/tb-statistics-india/.

[17] World Health Organization. Tuberculosis Country Profile Bangladesh. Geneva: WHO; (updated 2018, cited 18 December 2019). Available from: https://extranet.who.int/sree/Reports?op $=$ Replet\&name $=\% 2 \mathrm{~F}$ WHO_HQ_Reports\%2FG2\%2FPROD\%2FEXT\%2FTBCount ryProfile $\& \mathrm{ISO} 2=\mathrm{BD} \& \mathrm{LAN}=\mathrm{EN} \&$ outtype $=\mathrm{html}$.
[18] World Health Organization. Tuberculosis Country Profile India. Geneva: WHO; (updated 2018, cited 19 December 2019). Available from: https://extranet.who.int/sree/Reports?op=Replet\&name=\%2F WHO HQ Reports\%2FG2\%2FPROD\%2FEXT\%2FTBCount ryProfile \& $\overline{\mathrm{ISO}} 2=\mathrm{BD} \& \mathrm{LAN}=\mathrm{EN} \&$ outtype $=\mathrm{html}$.

[19] Furer V, Rondaan C, Heijstek MW, Agmon-Levin N, van Assen S, Bijl M, Breedveld FC, D'Amelio R, Dougados M, Kapetanovic MC, van Laar JM. 2019 update of EULAR recommendations for vaccination in adult patients with autoimmune inflammatory rheumatic diseases. Annals of the rheumatic diseases. 2020 Jan 1; 79 (1): 39-52. 